\title{
BUILDING ENERGY ANALYSIS OF AN INDUSTRIAL HALL BASED ON DYNAMIC SIMULATIONS
}

\author{
D. SZAGRI*, B. NAGY\& \\ Department of Construction Materials and Technologies, Faculty of Civil Engineering, Budapest University of Technology and \\ Economics, 1111 Budapest, Múegyetem rkp. 3. K.I.85., Hungary \\ *E-mail: szagridora@edu.bme.hu (Corresponding author) \\ \&E-mail: nagy.balazs@epito.bme.hu
}

\begin{abstract}
The aim of the paper is primarily to evaluate the heating energy demand of an industrial hall. In the study, we have made multidimensional dynamic whole building simulations for describing coupled heat and moisture behaviour and energy consumption of the building with different internal loads and compared to the calculated energy consumption of the building according to the Hungarian and Austrian regulations. The walls and roof structure of the industrial building were made with insulated panel systems, the plinth wall was built with monolithic reinforced concrete with $12 \mathrm{~cm}$ of XPS insulation. The floor is made of steel fibre reinforced concrete, where $10 \mathrm{~cm}$ XPS perimeter insulation was applied. After the calculations, we insulated the floor on the whole surface with $10 \mathrm{~cm}$ XPS and investigated the modified structure's heating energy demand too. In the paper, we analyse the energy consumption of the original and modified industrial building according to the monthly and seasonal calculations and the whole building dynamic simulations and evaluated the differences. Furthermore, we assessed the effect of internal loads, thermal bridges on the simulations.
\end{abstract}

Keywords: dynamic simulation, heat and moisture transfer, building physics, industrial hall

\section{Introduction}

Several dynamic whole-building simulations were performed for industrial and commercial buildings in recent years to assess the buildings' heating energy consumption or to recommend the best retrofit strategies for specific buildings [1-5]. Steady-state methods do not provide detailed information compared to simulations, and there is no such possibility to optimize the building's performance. Dynamic simulations can also be used to optimize the structural detail of a building in different climates [6]. The Energy Performance of Buildings Directive (EPBD) aims to promote improvements in the energy performance of buildings in Europe. A former comparison of energy certifications of buildings showed that EPBD is properly embedded into both the Hungarian and Austrian calculation systems and the calculation methodology has been developed for all building types [7]. In this paper we discuss the thermal performance of an industrial building, based on calculations according to the Hungarian
7/2006 TNM. Decree [8] and the Austrian OIB 6 Directive [9].

Furthermore, we conducted dynamic wholebuilding simulations coupled with thermal bridge simulation and analysed its effect on the heating energy consumption. Ge and Baba showed that the effect of three-dimensional thermal bridges is not negligible in dynamic simulations, and with increasing the insulation level, the effect of thermal bridges on annual heating load increases [10]. We have also evaluated the effect of different internal loads on the heating energy consumption with different thermal insulation designs. The main purpose of the research was to evaluate the heating energy consumptions calculated with the Hungarian regulation, the Austrian directive and with dynamic simulations, by setting the input parameters as close as possible. We also examined the effect of whole surface insulations in case of ground contact floors. Another goal was to analyse the effect of thermal bridges in case of dynamic simulations.

This is an open-access article distributed under the terms of the Creative Commons Attribution-NonCommercial 4.0 International License (https://creativecommons.org/licenses/by-nc/4.0/), which permits unrestricted use, distribution, and reproduction in any medium for non-commercial purposes, provided the original author and source are credited, a link to the CC License is provided, and changes - if any - are indicated. 


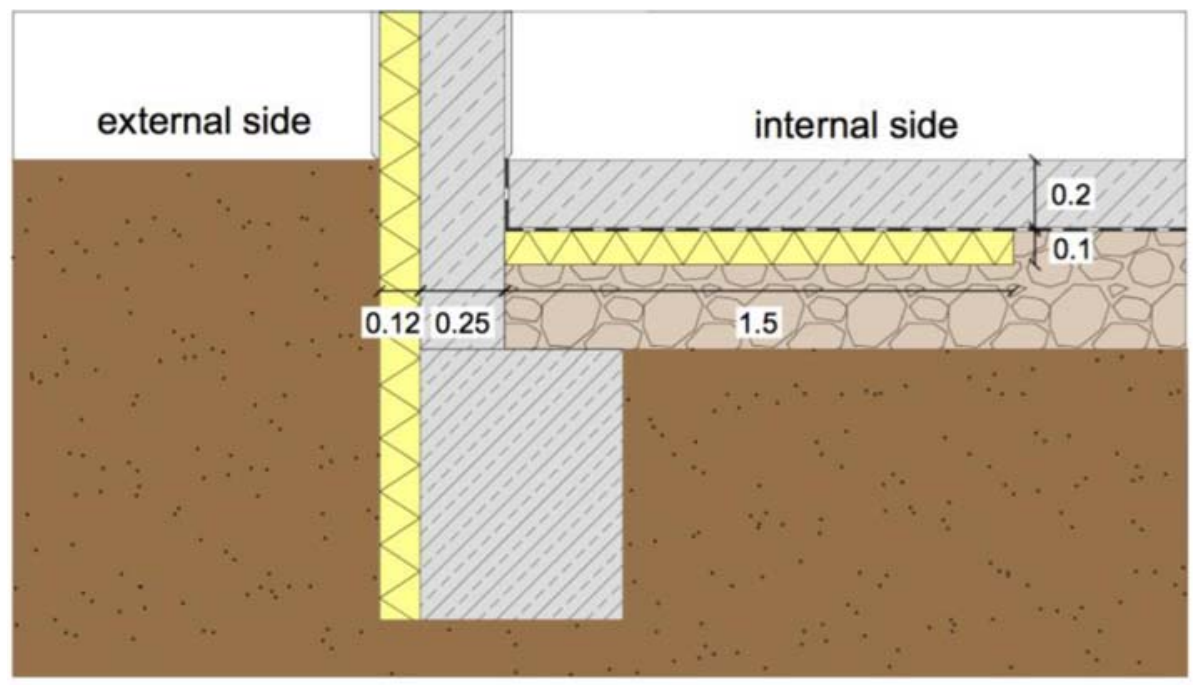

Fig. 1. Ground floor detail, thermal insulation design along the perimeter

\section{Analysed building and calculation methods}

The analysed industrial building functions as a car showroom and office with a floor area of $285.89 \mathrm{~m}^{2}$. According to the layout, there are two distinct units: a warehouse/exhibition hall and an office area, where a restroom, offices, kitchenette and mechanical room are located. The general requirements were $20{ }^{\circ} \mathrm{C}$, and $50-65 \%$ relative humidity in the hall.

The walls and roof structure of the industrial building were made with insulated panel systems, with $0.4-0.6 \mathrm{~mm}$ of metal skin and with $10 \mathrm{~cm}$ (walls) and $16 \mathrm{~cm}$ (roof) of IPN core thicknesses. In case of the industrial floor, along the perimeter of the fibre reinforced concrete floor, a $10 \mathrm{~cm}$ thick XPS insulation with a width of $1.5 \mathrm{~m}$ was applied (Fig. 1).
The plinth wall was built with $25 \mathrm{~cm}$ monolithic reinforced concrete, and $12 \mathrm{~cm}$ of XPS insulation, internal and external plaster layers were applied. The design of the office floor is similar to that of the exhibition hall, the difference between the two structures is that the used thermal insulation is applied over the entire surface of the floor. The geometry parameters of the industrial building are shown in Table 1.

The investigated building was examined according to two systems, based on the Hungarian 7/2006 TNM Decree [11] and the Austrian OIB 6 Directive [12]. These two calculations differ from one another in many respects, e.g. the values of the primary energy conversion factors are different. The heating in this building is provided by a condensing gas boiler with programmable heating control and the boiler also provides sanitary hot water in the office and washroom

Table 1. Geometry parameters of the industrial building

\begin{tabular}{lcccc}
\hline & Warehouse & Offices & Restroom & Mechanical room \\
\hline Net floor area & $247.73 \mathrm{~m}^{2}$ & $24.77 \mathrm{~m}^{2}$ & $6.00 \mathrm{~m}^{2}$ & $7.39 \mathrm{~m}^{2}$ \\
Net volume & $1578.83 \mathrm{~m}^{3}$ & $89.13 \mathrm{~m}^{3}$ & $20.48 \mathrm{~m}^{3}$ & $26.82 \mathrm{~m}^{3}$ \\
\hline
\end{tabular}

Table 2. Thermal transmittance values according to Hungarian and Austrian regulations

\begin{tabular}{lccc}
\hline \multirow{2}{*}{ Structure } & $7 / 2006 \mathrm{TNM}$ & OIB 6 & Original structure \\
\cline { 2 - 4 } & $\begin{array}{c}\text { Prescribed } U \text { value } \\
{\left[\mathrm{W} / \mathrm{m}^{2} \mathrm{~K}\right]}\end{array}$ & $\begin{array}{c}\text { Prescribed } U \text { value } \\
{\left[\mathrm{W} / \mathrm{m}^{2} \mathrm{~K}\right]}\end{array}$ & $\begin{array}{c}\text { Calculated } U \text { value } \\
{\left[\mathrm{W} / \mathrm{m}^{2} \mathrm{~K}\right]}\end{array}$ \\
\hline Wall & 0.24 & 0.35 & 0.21 \\
Plinth wall & 0.30 & 0.35 & 0.23 \\
Roof slab & 0.17 & 0.40 & 0.16 \\
Window & 1.15 & 1.40 & 1.10 \\
Ground floor & 0.30 & 0.40 & $3.82(0.47)$ \\
\hline
\end{tabular}


Table 3. Monthly external temperature (Temp.) and relative humidity (RH) values according to the Hungarian and Austrian regulations

\begin{tabular}{llccccccccccccc}
\hline & Months & I & II & III & IV & V & VI & VII & VIII & IX & X & XI & XII \\
\hline MSZ & Temp. $\left[{ }^{\circ} \mathrm{C}\right]$ & -2 & 0 & 5 & 13 & 19 & 22 & 25 & 23 & 18 & 12 & 5 & 0 \\
24140 & RH [\%] & 90 & 85 & 74 & 73 & 70 & 70 & 63 & 67 & 73 & 80 & 86 & 91 \\
\hline \multirow{2}{*}{ OIB 6 } & Temp. $\left[{ }^{\circ} \mathrm{C}\right]$ & -2.3 & 0.8 & 5.4 & 10.6 & 15.3 & 18.6 & 20.4 & 19.7 & 15.9 & 10 & 4.1 & -0.5 \\
& RH [\%] & 80 & 80 & 80 & 80 & 75 & 75 & 75 & 75 & 80 & 80 & 80 & 80 \\
\hline
\end{tabular}

area. In this case we have calculated using natural gas heating, so the conversion factors were different during the calculations (1.0 for the Hungarian and 1.17 for the Austrian), therefore the basis of the comparison was the heating energy consumption instead of primary energy consumption.

There is a significant difference between the prescribed thermal transmittance of the Hungarian and Austrian calculations, which can be seen in Table 2 alongside the $U$ values of the original structure. $U$ values shown are design values according to ISO 6946 [13], while for ground floor, in parentheses we gave the $U$ value according to ISO 13370 [14], too.

Another difference between the two calculation methods is the applied air exchange rate, which is 0.8 $1 / \mathrm{h}$ for commercial buildings in the Hungarian regulation and $1.0 \mathrm{l} / \mathrm{h}$ in the Austrian directive. However, the building belongs to the "other" category according to the Hungarian regulation, therefore we assumed 0.8 $1 / \mathrm{h}$ air exchange rate in the office, and $0.51 / \mathrm{h}$ in other parts of the building in Hungarian calculations and in dynamic simulations. It is also important to highlight the difference between the average outdoor temperature and relative humidity, as shown in Table 3.

During the calculations, thermal energy storage, heat losses through thermal bridges and heating energy demand were taken into account with a simplified method, to get comparable results. In case of ground contact floors, there is a remarkable difference between the simplified methods: the transmission losses are calculated according to the Hungarian regulation by multiplying the thermal resistance dependent linear thermal transmittance by the perimeter of the floor, but in the case of the Austrian Directive the floor area is multiplied by the $U$ value and with a 0.7 correction factor. When we evaluated the results, this lead to significant differences in the heat loss coefficients, therefore we calculated the ground contact structures according to ISO 13370 [14] in both cases and used those results in further calculations.

\section{Whole-building simulation}

In this research a coupled dynamic thermal bridge and whole-building simulation is performed too. We have used the WUFI Plus software for modelling the hygrothermal behaviour of the building. Because the boundary conditions - such as climate, heating, ventilation, air conditioning, internal loads - can be individually set by the user, the simulation provides accurate results for the building, as demonstrated by several validating processes. The validation with VDI 6020 and ASHRAE Standard 140-2007 performed by Antretter et al. showed good agreement, the calculation results are comparable with the reference values [15].

There are several methods for defining a building with the software, in this case we have used the building wizard for the base of the building, and 3D editor for the detailed parts. The entire building model can be seen in Fig. 2.

After the geometric design of the structural elements, the materials were defined from the built-in material database. We have divided the building into 4 different zones based on function: warehouse, office, restroom and mechanical room. The internal loads were defined on three aspects. Firstly, according to the Hungarian regulations: for offices the average heat gain is $7 \mathrm{~W} / \mathrm{m}^{2}$, which is divided into $1 / 3-2 / 3$ as convective and radiant load. Secondly, with group loads, where the values were selected from built-in values such as office, exhibition hall. Thirdly, based on individual data, where we adjusted to the exact func-

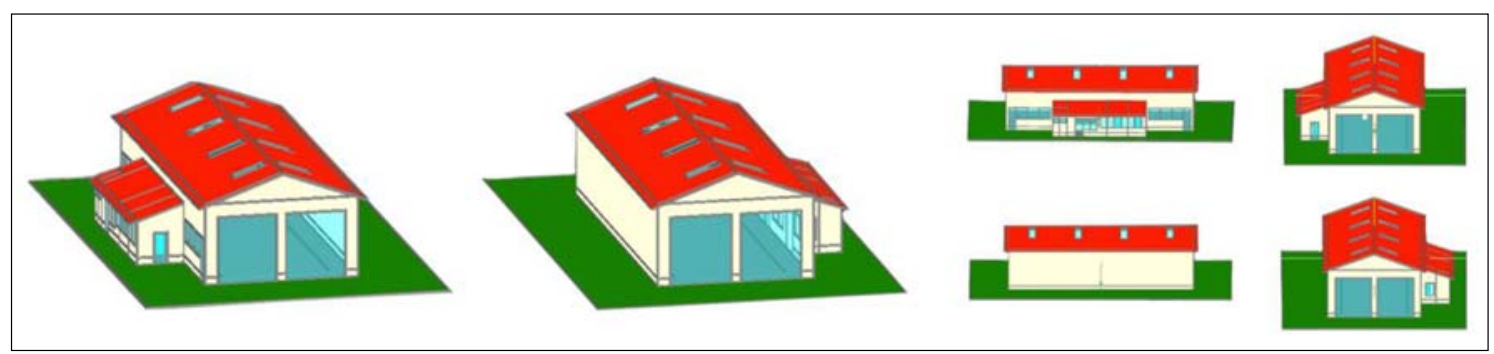

Fig. 2. Wufi Plus model of the examined building 


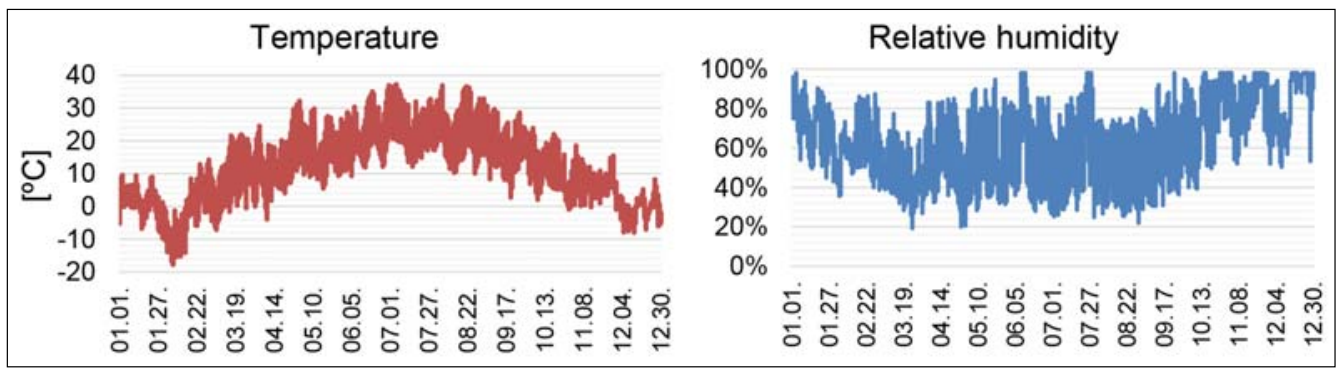

Fig. 3. Temperature and relative humidity distribution in Budapest during a year

tion of the building, including the number of people in the rooms, and the activity they are doing. For the external climate we used the weather in Budapest. The temperature and relative humidity values are shown in Fig. 3. During the calculations $1 \mathrm{~m}$ thick soil layer was taken into account, below that the temperature of the soil was calculated using a sinusoidal function with $13{ }^{\circ} \mathrm{C}$ mean value and $8^{\circ} \mathrm{C}$ amplitude at constant $90 \%$ relative humidity respecting the WUFI manual [16]. The natural infiltration rate is $0.51 / \mathrm{h}$ in the hall and in the office is $0.81 / \mathrm{h}$. The design conditions were set to a minimum and a maximum temperature and relative humidity for each zone; the minimum temperature was set to $20^{\circ} \mathrm{C}$ during working hours, and $16-17^{\circ} \mathrm{C}$ when no one is in the building.

Because the HVAC system supplies the whole building, we divided them between the zones. The heating was divided between the warehouse, the office, the restroom and the mechanical room with a ratio of $70 \%-20 \%-5 \%-5 \%$, respectively, as the warehouse has a substantial larger net volume and it is also necessary to keep the minimum temperature.

Wufi Plus is capable of integrating modules, which can be used for dynamic analysis of 3-dimensional bodies concurrently with the whole building. For this coupled thermal bridge and whole-building simulation, we have modelled the plinth wall section for each different part of the building with 19 components in total, because there are different boundary conditions based on the orientation and structure of the building. The software was validated successfully for modelling 2D and 3D thermal bridges according to DIN EN ISO 10211 by Antretter, Radon and Pa- zold [17], and with this combined application of the software the effect of thermal bridges to the overall performance can be evaluated, as well as moisture related problems on the thermal bridges. The run time of the simulations was 1.5 hour in general, and if $3 \mathrm{D}$ objects were specified, the running time increased to 8-9 hours. The results can be evaluated by zones. In this case, primarily the heating energy consumption was analysed and compared to the calculations.

\section{Results}

Comparing the results (Fig. 4), it can be seen that the calculations and simulations give different results. The calculations resulted in approximately $10 \%$ difference between the heating energy consumptions comparing the Hungarian and Austrian method. The difference between the simulations are more relevant, depending on what internal loads are applied to the structure, the difference between the heating energy consumption could be more than $20 \%$. It is also important to note that if the simulation of thermal bridges are neglected, the differences between the simulations can be more than $10 \%$ with the same internal load.

Analysing the transmission heat losses in a standard calculation, it is observable, that the effect of thermal bridges in the Austrian method are shown separately, in contrast to the Hungarian standard, where the effect of thermal bridges is included in the transmission heat losses. According to the Austrian calculation, their effect is $41.91 \mathrm{~W} / \mathrm{K}$ (with ON B 8110-6:2014-11-15 Form (12) method) and in the Hungarian calculation it is $17.28 \mathrm{~W} / \mathrm{K}$. In case

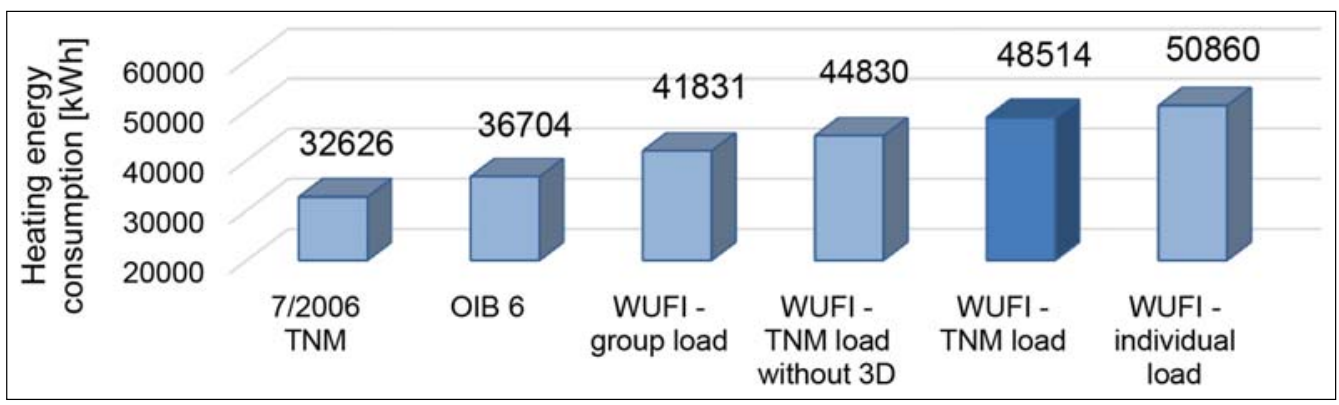

Fig. 4. Heating energy consumptions with different methods and loads 


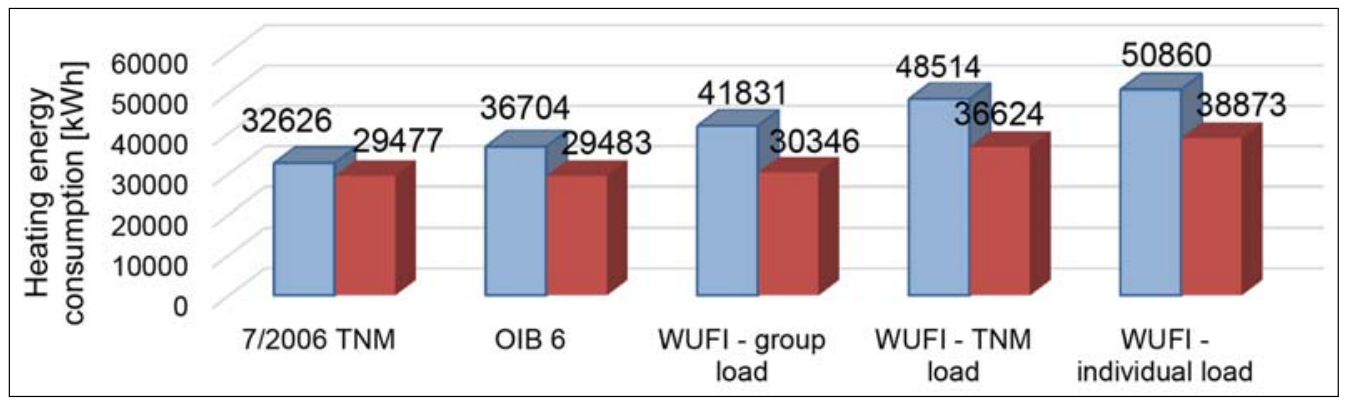

Fig. 5. Heating energy consumption original (blue) and modified structure (red)

of ground floors, the transmission losses would be $79.29 \mathrm{~W} / \mathrm{K}$ according to the Hungarian regulation, in contrast, $637.46 \mathrm{~W} / \mathrm{K}$ according to the Austrian Directive. Taking into account the $1.5 \mathrm{~m}$ perimeter insulation these values are $38.38 \mathrm{~W} / \mathrm{K}$ (Hungarian) and $48.03 \mathrm{~W} / \mathrm{K}$ (Austrian) with using national regulations. Therefore, we used ISO 13370 for the final results, where the floor's ground heat loss was 89.09 $\mathrm{W} / \mathrm{K}$ in both cases. The overall transmission losses are $403.21 \mathrm{~W} / \mathrm{K}$ in case of the Hungarian regulation and $434.57 \mathrm{~W} / \mathrm{K}$ with the Austrian method. In case of large floor area buildings, the Hungarian simplified method does not provide reliable result, because the heat loss will be smaller compared to the values calculated with MSZ EN ISO 13370:2017 standard [18].

\section{Modified structure}

Based on the results we were interested in how the thermal performance of the building is improved if the floor of the warehouse is not only insulated along the perimeter, but we use a $10 \mathrm{~cm}$ insulation on the entire surface. With this correction, we have made the energy calculations as well as three-dimensional simulations, the results are shown in Fig. 5.

By comparing the heating energy consumption, after the structural change the difference between sim-

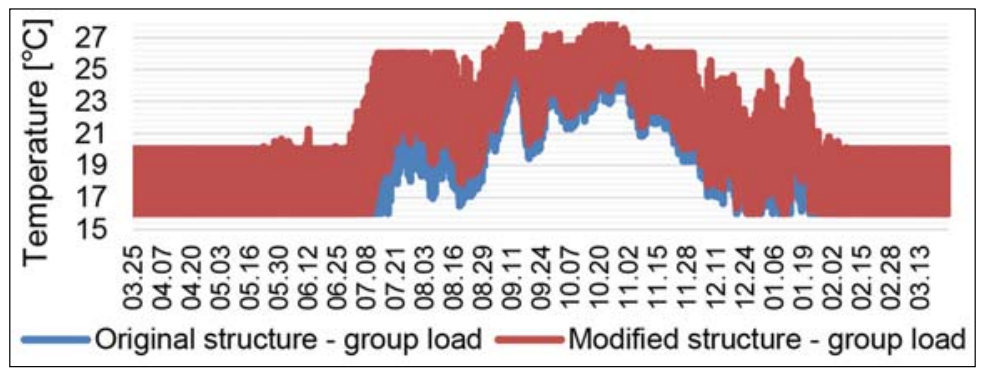

Fig. 6. Internal temperature in the warehouse
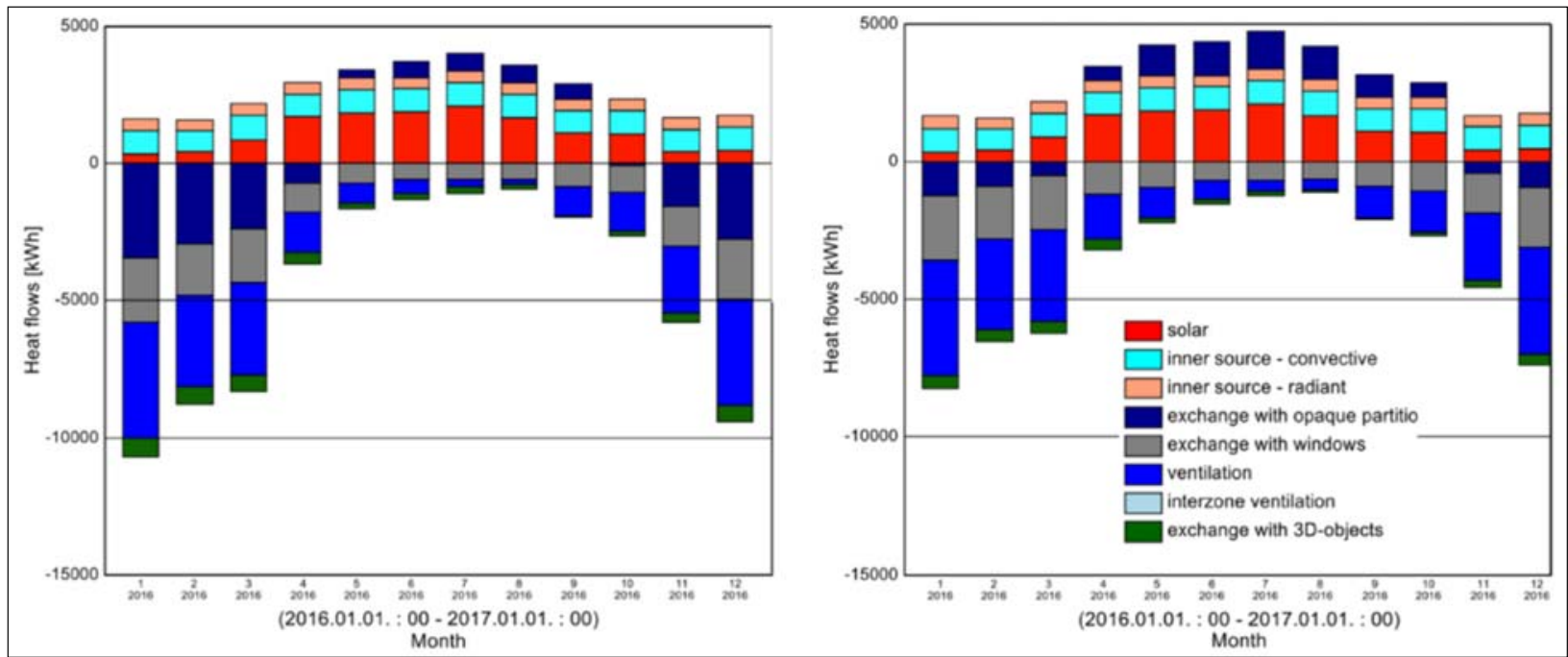

Fig. 7. Monthly heat flows in warehouse with original and modified structure (TNM load) 
ulated and calculated results are smaller. The calculated results decreased by $10-20 \%$, while the values of the simulations could decrease by $25 \%$. In total, the maximum heating energy consumption was achieved with the original structure with individual loads, as in this case we gave a much smaller load as an input parameter. The smallest heating energy consumption was achieved with group loads, since in this case the internal load is the highest, thus the internal heat production and moisture load is higher too, resulting in the lowest heating energy consumption. Based on the results, it is important to note that, compared to the value based on the regulation, the annual heating energy consumption in case of dynamic simulations may increase by up to $10 \%$ by using different loads. Comparing the temperature in the warehouse in case of two different structures (Fig. 6), it can be seen, that depending on the structure, the temperature of the internal air also varies. In the case of the original structure (with perimeter insulation) the temperature of the warehouse can cool down more in the summer, than in the whole surface insulated case. There is also a minimal difference in relative humidity due to the modification of the structure.

Figure 7 shows the monthly heat flows in the two different structures with the same internal load. It is apparent that the heat exchange with the structural elements is much smaller in the fully insulated case, so the heating energy consumption changes in a much more favourable direction.

\section{Conclusions}

In the presented paper, we examined the heating energy consumption, and energy performance of an industrial building by using Hungarian and Austrian regulations. We conducted dynamic whole building simulations and compared the results to the calculations and evaluated the effect of three-dimensional thermal bridges in the simulation. In addition, we analysed the effect of whole surface ground insulation on the heating energy consumption.

Comparing the energy consumption of heating, it can be seen, that the calculations for the given building showed different results. These differences may arise from the above mentioned inequality of the calculation methods, and from the possibilities of setting up the heating system. It is worth mentioning that in the calculations it is very important to use the available simplifications correctly to get reliable results. In contrast, the simulated model with similar internal loads resulted in significantly higher heating energy consumption. The difference between the results is mainly due to the fact that the calculation methods are seasonal (Hungarian), monthly (Austrian) and hourly (simulation) based. It is essential to consider the effect of three-dimensional thermal bridges in the simulation, because the difference in the results can be almost $10 \%$.

With using full surface floor insulation instead of perimeter insulation, the heating energy consumption can be reduced by at least $\sim 10 \%$ in the analysed building; if we take into account the expected additional construction cost, it is worthwhile to insulate the whole floor in the warehouse, primarily because the floor area of the building is small. With dynamic simulations, heat losses and gains can be evaluated grouped by components, and with the additional information of temperatures, relative humidities and water contents, the possible problems within the structures can be discovered to help optimizing the building structures' design process. With coupled thermal bridge simulations, the temperatures and heat fluxes can be analysed too in the pre-set monitoring points, also assisting the design progress.

\section{Acknowledgements}

Authors are gratefully acknowledge Auricon Mérnöki $\mathrm{Kft}$ (Auricon EnergetiC), A-NULL Development GmbH (Archiphysik) and Fraunhofer IBP (WUFI Pro) for providing us their software. Support of grant BME FIKP-VÍZ by EMMI is kindly acknowledged.

\section{References}

[1] Sheng Y., Miao Z., Zhang J., Lin X., Ma H. (2018), Energy consumption model and energy benchmarks of five-star hotels in China. Energy and Buildings, 165, 286-292.

[2] Silenzi F., Priarone A., Fossa M. (2018), Hourly simulations of an hospital building for assessing the thermal demand and the best retrofit strategies for consumption reduction. Thermal Science and Engineering Progress, 6, 388-397.

[3] Gourlis G., Kovacic I. (2016), A study on building performance analysis for energy retrofit of existing industrial facilities. Applied Energy, 184, 1389-1399.

[4] Simson R., Fadejev J., Kurnitski J., Kesti J., Lautso P. (2016), Assessment of retrofit measures for industrial halls: Energy efficiency and renovation budget estimation. Energy Procedia, 96, 124-133.

[5] Kuusk K., Kurnitski J., Kalamees T. (2017), Calculation and compliance procedures of thermal bridges in energy calculations in various European countries. Energy Procedia, 132, 27-32.

[6] Nagy B., Szagri D. (2017), Dynamic heat and moisture transport modeling of industrial floors on different climates. Applied Mechanics and Materials, 861, 271-278.

[7] Andaloro A. P. F., Salomone R., Ioppolo G., Andaloro L. (2010), Energy certification of buildings: A comparative analysis of progress towards implementation in European countries. Energy Policy, 38(10), 5840-5866.

[8] TNM Decree, No. 7/2006., http://njt.hu/cgi_bin/njt_doc. cgi?docid=101820.352718 (last visited 20 July 2018). 
[9] OIB-Richtlinie 6, Energieeinsparung und Wärmeschutz, https://www.oib.or.at/de/oib-richtlinien/richtlinien/2015/ oib-richtlinie-6 (last visited 20 July 2018).

[10] Ge H., Baba F. (2015), Dynamic effect of thermal bridges on the energy performance of a low-rise residential building. Energy and Buildings, 105, 106-118.

[11] Auricon EnergetiC 2.9.0. User's Manual, 2018.

[12] ArchiPHYSIK 14.0.116. User's Manual, 2017.

[13] ISO 6946:2017. Building components and building elements - Thermal resistance and thermal transmittance Calculation methods

[14] ISO 13370:2017. Thermal performance of buildings Heat transfer via the ground - Calculation methods
[15] Antretter F., Sauer F., Schöpfer T., Holm A. (2011), Validation of a hygrothermal whole building simulation software. In: Proceedings of Building Simulation 2011: 12th Conference of International Building Performance Simulation Association, pp. 1694-1701.

[16] WUFI Plus V.3.3.1.0. User's Manual, 2017

[17] Antretter F., Radon J., Pazold M. (2013), Coupling of dynamic thermal bridge and whole building simulation. In: Thermal Performance of the Exterior Envelopes of Whole Buildings XIIth International Conference, pp. 693-701.

[18] Nagy B. (2017), Building physics of ground contact structures, 3rd part: Large-scale ground contact floors (in Hungarian). Megtérülő Épületenergetika, 4(2), 35-40. 